\title{
LAPAROSCOPIC CHOLECYSTECTOMY UNDER SPINAL ANAESTHESIA: STUDY IN 100 CASES
}

\author{
Niranjan Kumar Verma ${ }^{1}$
}

1 Professor \& HOD, Department of Anaesthesiology, Jawaharlal Nehru Medical College \& Hospital, Bhagalpur.

\section{ABSTRACT}

\section{BACKGROUND}

Laparoscopic cholecystectomies are generally performed under general anaesthesia. Trials for spinal anaesthesia were not satisfactory. My experience on 100 cases with a modified technique provided very good results, where Bupivacaine and Clonidine were administered by subarachnoid route combined with peritoneal insufflation and local infiltration of Ropivacaine.

\section{METHOD}

One hundred ASI grade 1 and grade 2 patients undergoing elective laparoscopic cholecystectomy opting for spinal anaesthesia were given $1 \mathrm{~mL}(150 \mathrm{mcg})$ of clonidine in L1-L2 interspace followed by $3 \mathrm{~mL}(15 \mathrm{mg})$ of $0.5 \%$ heavy bupivacaine in the same interspace by separate syringes, 15 degrees head down tilt, intra-peritoneal insufflation of $0.5 \%$ Ropivacaine just after pneumoperitoneum and cannula insertion and lastly local infiltration of $0.5 \%$ Ropivacaine $2 \mathrm{~mL}$ at each incision at the time of skin closure. Preemptive 10-15 mg of Mephentermine IM was given to each patient. Recordings of vital parameters, pain experienced by patients, especially excruciating shoulder pain, any difficulty experienced by surgeons, need for analgesia, level of consciousness, respiratory depression, hypotension, bradycardia, pruritus were recorded at frequent intervals during operation and later in the ICU for prompt managements.

\section{RESULTS}

None of the patients experienced any pain in the peri- and post-operative period, analgesia was excellent for 12-16 hours postoperatively. No respiratory depression, severe bradycardia, hypotension or pruritus was noticed. Incidence of post-operative nausea and vomiting were negligible.

\section{CONCLUSION}

Clonidine as adjuvant with hyperbaric Bupivacaine in spinal anaesthesia combined with intraperitoneal infiltration of $20 \mathrm{~mL}$ of $0.5 \%$ Ropivacaine just after insertion of cannula through an irrigation cannula and $2 \mathrm{~mL}$ of $0.5 \%$ Ropivacaine injected at each port site at the time of skin stitches, when given in proper way can be a very good alternative to general anaesthesia for upper abdominal surgeries and especially for Laparoscopic Cholecystectomy without any unmanageable difficulty to the patient and ease for the surgeon. The cost factor is also very favourable. It can be practiced particularly in field situations and remote areas.

\section{KEYWORDS}

Laparoscopic Cholecystectomy, Bupivacaine, Ropivacaine, Clonidine, Preemptive Mephentermine, Intraperitoneal Insufflation, Head Down Tilt, Local Infiltration.

HOW TO CITE THIS ARTICLE: Verma NK. Laparoscopic cholecystectomy under spinal anaesthesia: study in 100 cases. J. Evolution Med. Dent. Sci. 2016;5(62):4387-4391, DOI: 10.14260/jemds/2016/1001

\section{INTRODUCTION}

Upper abdominal operations, particularly Laparoscopic Cholecystectomy can well be undertaken with spinal anaesthesia using 0.5\% heavy Bupivacaine and Clonidine as adjuvant supplemented by $0.5 \%$ Ropivacaine given by intraperitoneal insufflation plus local infiltration at port incisions, gives very good outcome if right technique is used. Spinal anaesthesia with local anaesthetic agents and adjuvants are extensively used nowadays for lower abdominal or lower limb orthopaedic surgeries, ${ }^{[1-4]}$ as it provides excellent intraoperative and postoperative pain relief for variable duration as compared to intravenous or epidural routes. Neuraxial opioids as adjuvant may cause worrisome adverse effects like potentially catastrophic respiratory depression, urinary retention, vomiting and

Financial or Other, Competing Interest: None.

Submission 17-05-2016, Peer Review 16-07-2016,

Acceptance 22-07-2016, Published 04-08-2016.

Corresponding Author:

Dr. Niranjan Kumar Verma,

Mayaganj Doctor's Colony,

Opposite JLNMC \& H, Mayaganj,

Bhagalpur-812001, Bihar.

E-mail: nkverma2001@yahoo.com

DOI: $10.14260 / \mathrm{jemds} / 2016 / 1001$ pruritus, etc., limiting their use in less developed setup.[5-7] So, non-opioid compounds with analgesic property and less adverse effects were promoted. Intrathecal clonidine produces a dose-dependent anti-nociception when used in combination with local anaesthetics.[5,8] Clonidine when combined with local anaesthetic agents improve intraoperative analgesia, prolong duration of sensory and motor blockade along with sparing effect on postoperative analgesic consumption.[9] The incidence of hypotension, bradycardia and sedation observed with intrathecal clonidine in earlier studies is reduced using low dose of clonidine (150 mcg or less).[5] However, upper abdominal operations, particularly laparoscopic cholecystectomy are rarely undertaken with spinal anaesthesia with good results for fear of right shoulder pain and difficulty experienced by the surgeons. I have studied this modified process in 100 cases and observed satisfactory results in almost all cases without any complication.

My trial was conducted during December 2014 to March 2016, comprising of 100 patients who opted for spinal anaesthesia (And not general anaesthesia) selected for Laparoscopic Cholecystectomy. In our part of India where many a times the patient or their relatives are afraid of 
general anaesthesia and insists upon the operations to be done in conscious state. Cost factor is also relevant. Lower abdominal operations of general surgery, obstetrics and gynaecology surgery and hip and lower limb surgery under spinal anaesthesia are practiced worldwide. But here at Bhagalpur, Bihar, I have to undertake upper abdominal surgery under spinal anaesthesia very frequently due to aforesaid reasons. Cholecystitis and accompanied cholelithiasis is very prevalent in this region, so the major part of upper abdominal surgery comprises of cholecystectomy itself and the majority of them were Laparoscopic-Cholecystectomy.

My present study is based on the effects of addition of Clonidine $150 \mathrm{mcg}$ to $0.5 \%$ heavy bupivacaine given with separate syringes in spinal anaesthesia for Laparoscopic Cholecystectomy operations, supplemented with intraperitoneal insufflation of $20 \mathrm{~mL}$ of $0.5 \%$ Ropivacaine. I used $150 \mathrm{mcg}$ of clonidine and $15 \mathrm{mg}$ of hyperbaric $0.5 \%$ bupivacaine separately in L1-L2 interspace with 15 degrees head down tilt. After the insertion of ports by the surgeon and producing low pressure pneumoperitoneum $(8 \mathrm{mmHg})$, before initiating the actual surgical procedure, $20 \mathrm{~mL}$ of $0.5 \%$ Ropivacaine was instituted intraperitoneal through the irrigation cannula, furthermore $2 \mathrm{~mL}$ of $0.5 \%$ Ropivacaine was injected at each port incisions just prior to skin closure. Preemptive $15 \mathrm{mg}$ of Mephentermine was given intramuscular for fear of hypotension and then the surgeon was allowed to proceed for surgery.

\section{Effects were Studied Regarding}

(1) Onset of sensory and motor paralysis, (2) Height of sensory and motor paralysis, (3) Density of Paralysis, (4) Need for any intravenous supplementation of narcotic analgesic, (5) Intraoperative hypotension or bradycardia, nausea or vomiting, rigor, respiratory depression, any sedation, abdominal relaxation and ease to the surgeons, (6) Regression of analgesia, (7) Total duration of analgesia and (8) Time for the need of first systemic administration of postoperative analgesia.

\section{MATERIALS AND METHODS}

After taking formal approval by Hospital Ethical Committee, informed consents were obtained from all the participants. One hundred patients of either sex in age groups 25-55 years belonging to ASA physical status I or II and scheduled for Laparoscopic cholecystectomy who opted for spinal anaesthesia were included in the present study. The patients on cardiovascular medications, those with history of hypersensitivity to clonidine or bupivacaine and ropivacaine, and those with conditions that preclude spinal anaesthesia were excluded from the study.

All patients were examined preoperatively and details regarding clinical history and general physical examination were recorded. All routine investigations were carried out. During the pre-anaesthetic visit, every patient was familiarized with linear visual analog scale (VAS $0=$ no pain and VAS 10 = worst imaginable pain).[10] Oral alprazolam $0.25 \mathrm{mg}$ was given the previous night. Patients were kept fasting for 6 hours, Glycopyrrolate $0.2 \mathrm{mg}$ intramuscular was given to all patients for fear of vagal stimulation and then they were brought to the operation room. Intravenous (IV) line was established and standard monitors like Non-Invasive
Blood Pressure (NIBP), Pulse Oximeter (SpO2) and Electrocardiography (ECG) were attached. Basal readings of heart rate, blood pressure were recorded. IV preloading was done with $500 \mathrm{~mL}$ of Ringer lactate solution over a period of 15 minutes.

Before starting the procedure, all necessary equipment for endotracheal intubation and mechanical ventilation, anaesthesia machine, pressure support drugs and intravenous analgesic drugs were kept in ready position. Three bottles $(100 \mathrm{~mL})$ of Intralipid $20 \%$ were also kept ready for fear of local anaesthetic toxicity management.

Patients were placed on right lateral position. After full aseptic preparations, $150 \mathrm{mcg}(1 \mathrm{~mL})$ of preservative free clonidine was loaded in a $1 \mathrm{~mL}$ syringe and $3 \mathrm{~mL}$ of $0.5 \%$ heavy bupivacaine $(3 \mathrm{~mL})$ was loaded in a $5 \mathrm{~mL}$ syringe separately; $1 \mathrm{~mL}$ of $1 \%$ lidocaine was injected in L1-L2 interspace. A 27-G spinal needle was inserted in this space and free flow of Cerebrospinal Fluid (CSF) was ascertained; 150 mcg of clonidine was injected first, keeping the patient in horizontal and right lateral position. After one minute, $3 \mathrm{~mL}$ of $0.5 \%$ healthy bupivacaine was injected in the subarachnoid space, spinal needle withdrawn, patient brought to supine position, a $6-\mathrm{cm}$ pillow put under the shoulder and a 15 degrees definite head down tilt was given; all this in very quick succession without delay. Preemptive 10-15 mg of Mephentermine was injected deep intramuscularly. After ascertaining analgesia level reaching nipple line (T4) by pin prick method, time taken to achieve this level was recorded.

Patients were brought back to horizontal position after 10 minutes, the surgical process was allowed asking the surgeon for a low pressure $(8 \mathrm{mmHg}$ ) of $\mathrm{CO} 2$ pneumoperitoneum with a gas flow of 2 litre per minute. After the insertion of ports by the surgeon and producing low pressure pneumoperitoneum ( $8 \mathrm{mmHg}$ ) before initiating the actual surgical procedure, 15 $\mathrm{mL}$ of $0.25 \%$ Ropivacaine was instituted intraperitoneally through the irrigation cannula, surgeon was allowed to proceed. Pulse rate, Blood pressure, SpO2 level and any pain complained by the patient or any difficulty noticed by the surgeon was documented every 5 minutes. Fall in blood pressure was tided over by fast IV infusion and bradycardia with Atropine IV in diluted form (1 ampule of Atropine [0.6 mg] diluted with distilled water to make it $5 \mathrm{~mL}$ and 1 $\mathrm{mL}$ of the solution injected at a time to titrate the desired effect).

Some patients showed incidence of shivering during the intra- and post-operative period and was instantly checked by administering $50-100 \mathrm{mg}$ of Tramadol by slow intravenous injection.

After the conclusion of the operative procedure, before skin stitches, $2 \mathrm{~mL}$ of $0.5 \%$ Ropivacaine was injected superficially at each incision. Total duration of surgery, degree of motor and sensory block, level of consciousness and respiratory pattern with all other vital parameters were noted and patient shifted to post-operative surgical ICU for further assessment and management for next 48 hours.

\section{Degree of Motor Block was Assessed by Modified Bromage Scale as follows:}

Scale 1: Free movement of leg and feet.

Scale 2: Just able to flex knees with free movement of feet.

Scale 3: Unable to flex knee, but with free movement of feet.

Scale 4: Unable to move leg and feet. 
Motor block was assessed at the same intervals as sensory block. Time to achieve maximum degree of block as per modified Bromage scale and its regression to Bromage I was noted. Sedation score was also assessed at the same interval as sensory block. Sedation was assessed by modified Ramsay Sedation Scale.

Scale 1: Anxious, agitated, restless.

Scale 2: Cooperative, oriented, tranquil.

Scale 3: Responds to commands only.

Scale 4: Brisk response to light glabellar tap or loud noise.

Scale 5: Sluggish response to light glabellar tap or loud noise. Scale 6: No response.

Response to pain score was recorded by Visual Analog Pain Scale (VAS) between 0 and $10(0=$ no pain, $10=$ most severe pain). Postoperatively, VAS was recorded initially every $1 \mathrm{hr}$. for $2 \mathrm{hrs}$., then every $2 \mathrm{hrs}$. for the next $8 \mathrm{hrs}$. and then every 4 hrs. till 24 hrs. Inj.

Rescue analgesia in the form of diclofenac sodium $75 \mathrm{mg}$ intramuscularly was administered whenever VAS was $<4$. This time to rescue analgesia (Time for first analgesic request) was noted. Intraoperative analgesia was not required in any case. Haemodynamic parameters of the patient before the block (Basal), every 5 mins. after the block for 30 mins., every 15 mins. until 6 hours after the intrathecal administration were recorded. Any episode of hypotension or bradycardia in 24 hours was noted and treated. Hypotension was defined as a $20 \%$ reduction in systolic blood pressure from the baseline or systolic below $90 \mathrm{mmHg}$. Bradycardia was defined when the heart rate dropped to 50 beats per minute or $<20 \%$ of base value. Incidence of adverse effects such as nausea, vomiting, shivering, postoperative after the completion of surgery.

\section{RESULTS}

\section{Observations were recorded in following Parameters}

\begin{tabular}{|l|l|}
\hline T-0 & Time of Full Spinal Anaesthesia Procedure \\
\hline T-1 & Time of Onset of Sensory Block \\
\hline T-2 & Time of Onset of Motor Block \\
\hline T-3 & Time of Peak Sensory Block \\
\hline T-4 & Time of 2 Segment Regression of Sensory Block \\
\hline T-5 & Time of Wearing off of Sensory Block \\
\hline T-6 & Time of 1st Dose of Post-Operative Rescue Analgesia \\
\hline
\end{tabular}

Residual sensory block was monitored and its wearing off time was noted (When sensation to pin prick regressed by 2 dermatomal segment). Residual motor blockade was monitored and its wearing off time was noted (When patient started lifting the leg against gravity). Patients were inquired frequently for degree of pain they felt with the help of VAS. Rescue analgesia in the form of Diclofenac $75 \mathrm{mg}$ intramuscular was given when patient's VAS score reached $>4$ and the time of injection was noted. This was taken as wearing of analgesia.

\begin{tabular}{|c|c|}
\hline Characteristics & Values \\
\hline Ages in Years & $40.0 \pm 15$ \\
\hline Weigh in K.G. & $51.65 \pm 11.73$ \\
\hline Height in CM & $153.45 \pm 6.79$ \\
\hline Duration of Surgery in Minutes & $61.54 \pm 15.86$ \\
\hline Demographic Characteristics \\
\hline
\end{tabular}

\begin{tabular}{|c|c|}
\hline Parameters & Values \\
\hline $\begin{array}{c}\text { Basal Pulse } \\
\text { Rates in Minutes }\end{array}$ & $88 \pm 13.14$ \\
\hline $\begin{array}{l}\text { Basal Systolic Blood } \\
\text { Pressure in mmHg }\end{array}$ & $118.94 \pm 7.78$ \\
\hline $\begin{array}{l}\text { Basal Diastolic Blood } \\
\text { Pressure in mmHg }\end{array}$ & $77.47 \pm 8.06$ \\
\hline Average Pulse Rate & $88.53 \pm 14.08$ \\
\hline $\begin{array}{c}\text { Average Systolic } \\
\text { Blood Pressure }\end{array}$ & $111.24 \pm 10.43$ \\
\hline $\begin{array}{l}\text { Average Diastolic } \\
\text { Blood Pressure }\end{array}$ & $63.52 \pm 9.61$ \\
\hline $\begin{array}{c}\text { No. of Occasion of } \\
\text { Bradycardia }(P R<50)\end{array}$ & 6 \\
\hline $\begin{array}{c}\text { No. of Occasions of } \\
\text { Tachycardia }(P R>120)\end{array}$ & 2 \\
\hline $\begin{array}{l}\text { No. of Occasions } \\
\text { of Hypotension }\end{array}$ & 7 \\
\hline Sp02\% & $91-99 \%$ \\
\hline $\begin{array}{l}\text { Abdominal } \\
\text { Relaxation }\end{array}$ & Excellent \\
\hline $\begin{array}{c}\text { Ease to the } \\
\text { Surgeon }\end{array}$ & Absolute \\
\hline $\begin{array}{l}\text { Incidence of Agonizing } \\
\text { Shoulder Pain }\end{array}$ & 0 \\
\hline $\begin{array}{l}\text { Post-Operative Nausea } \\
\text { and Vomiting }\end{array}$ & 2 \\
\hline Shivering & 23 \\
\hline Respiratory Depression & 0 \\
\hline Sedation & $\begin{array}{c}\text { Modified Ramsay } \\
\text { Sedation Scale } 2 \\
\end{array}$ \\
\hline \multicolumn{2}{|c|}{ Haemodynamic Parameters } \\
\hline
\end{tabular}

\begin{tabular}{|c|c|}
\hline Parameters & Values \\
\hline $\begin{array}{c}\text { Time in Minutes for Onset } \\
\text { of Sensory Blockade }\end{array}$ & $0.92 \pm 0.18$ \\
\hline $\begin{array}{c}\text { Time of Onset of } \\
\text { Motor Blockade }\end{array}$ & $1.79 \pm 0.53$ \\
\hline $\begin{array}{c}\text { Time of Onset of Peak } \\
\text { Sensory Blockade }\end{array}$ & $7.44 \pm 1.89$ \\
\hline $\begin{array}{c}\text { 2 Segment Regression Time in } \\
\text { Minutes for Sensory Blockade }\end{array}$ & $237.2 \pm 21.47$ \\
\hline $\begin{array}{c}\text { Time in Minutes for Wearing } \\
\text { off of Motor Blockade }\end{array}$ & $188.6 \pm 10.81$ \\
\hline $\begin{array}{c}\text { Time in Minutes for 1st } \\
\text { Rescue Analgesia }\end{array}$ & $848.5 \pm 104.5$ \\
\hline Motor and Sensory Block Parameters \\
\hline \multicolumn{2}{|c|}{}
\end{tabular}

\section{DISCUSSION}

Spinal adjuvant drugs have been used since the beginning of subarachnoid anaesthesia. Adrenaline, an alpha-2 agonist, was the first drug used to enhance duration of spinal anaesthesia and morphine was the first opioid injected with eucaine in the lumbar spinal space to relieve vertebral pain.[14] After the first article on spinal analgesia using opioids written by Yaksh and Rudy in 1976,[7] the neuraxial route to inject opioids as adjuvant drugs grew logarithmically. Morphine, fentanyl, sufentanil and many more agonist opioids have proven their safety and efficacy to decrease the dose of local anaesthetic to facilitate a faster recovery and effective postoperative analgesia. There are many receptors which modulate spinal pain response; however, there are only a few FDA approved drugs to be used via subarachnoid as adjuvants or sole medications. 
Many drugs are being injected into the spinal or epidural space in order to provide analgesia and/or to enhance neuraxial anaesthesia. Nowadays, opioids are the more frequently used spinal additives, but their side effects may limit its use; pruritus, urinary retention and late respiratory depression. There are studies with intrathecal adjuvants like midazolam, ketamine, neostigmine, magnesium sulphate, calcium channel blockers, non-steroidal anti-inflammatory, Dexmedetomidine, tizanidine.[11-13]

Alpha-2 agonist medications are used as adjuvants in anaesthesia and analgesia.[12,14,15] They can be prescribed orally, transdermally, intravenously, perineuraly or through the neuraxial route. Beside analgesia and sedation, they decrease sympathetic tone and attenuate the stress response to anaesthesia and surgery. Although adrenaline was the first alpha-2 agonist used intrathecally, it is no longer recommended. Nowadays, clonidine is the most used alpha-2 agonist in neuraxial anaesthesia, even though Dexmedetomidine has also recently gained popularity for epidural and spinal anaesthesia adjuvant. Clonidine acts as a selective partial agonist with a ratio of 200:1, whereas Dexmedetomidine is highly selective with a ratio of 1600:1. Tizanidine, 5-bromo-N-[4, 5-Dihydro-1H-imidazol-2-yl)-6quinoxalinamine (UK-14, 304] and moxonidine are other alpha- 2 agonists with a potential neuraxial use.[14,15]

Clonidine was synthesized in 1960 and marketed as nasal decongestant in 1962, and then started being used as antihypertensive from 1972. Soon after clonidine has been used by Anaesthesiologists as an anaesthetic adjunct to provide increased perioperative cardiovascular and sympathoadrenal stability to enhance general and regional anaesthesia as well as sedation and analgesia.[12,16,17]

Clinical studies in humans performed with intrathecal injection of clonidine have shown its analgesic effects with fewer side effects than any other neuraxial anaesthesia adjuvant.

Intrathecal administration of clonidine is an interesting route of administration. As an alpha-2 agonist, spinal injected clonidine prolongs sensory and motor block, increases sedation and may potentiate hypotension and bradycardia. It has been used in high $(>150 \mu \mathrm{g})$, low $(<150 \mu \mathrm{g})$ and small $(<75 \mu \mathrm{g})$ doses. High doses 150, 300 and $450 \mu \mathrm{g}$ produce dose dependent analgesia, enhance spinal anaesthesia with relative haemodynamic stability.[3] Furthermore, doses of 15 and $30 \mu \mathrm{g}$ in addition to spinal local anaesthetic provide better sensory and motor block compared to local anaesthetic alone. [2]

The optimal dose of spinal clonidine remains unknown. For short ambulatory procedures 15 to $75 \mu \mathrm{g}$ added to local anaesthetic enhance spinal anaesthesia without negative impact on home discharge criteria. For short stay or longer hospitalisation surgeries, doses from 150 up to $450 \mu \mathrm{g}$ of clonidine as adjuvant for any local anaesthetic are safe, prolongs motor and sensory block and reduces the need of postoperative opioids.[3]

Clonidine is an imidazoline derivative that exists as a mesmeric compound. It has a molecular weight of 266.56, chemical name is Benzenamine, 2, 6-dichloro-N-2imidazolindinylidene monohydrochloride and 2-[[2, 6dichlorophenyl) amino] imidazoline monohydrochloride. Its structural formula is $(\mathrm{C} 9 \mathrm{H} 9 \mathrm{Cl} 2 \mathrm{~N} 3 \mathrm{HCl})$. Clonidine stimulates alpha-2 adrenoceptors in the brain and spinal cord, $[7,15,18]$ resulting in reduction of sympathetic outflow from the central nervous system and decreased in peripheral resistance, renal vascular resistance, plasma renin activity, heart rate, cardiac output and blood pressure.[14,16] Normal postural reflexes are intact; therefore, orthostatic symptoms are mild and infrequent. Plasmatic level of clonidine peaks in approximately 3 to 5 hours and the plasma half-life ranges from 12 to 16 hours. The half-life increases up to 41 hours in patients with severe renal impairment. Following oral administration, approximately $75 \%$ is bioavailable in men, about $40-60 \%$ of the absorbed dose recovered unchanged in the urine in 24 hours. About $50 \%$ of the absorbed dose is metabolized in the liver. Severe adverse side effects are infrequent and well tolerated in most patients. Sedation and dry mouth are the most common side effects and are usually related to dose and length of administration.[11,12,16,17]

Mechanisms of action of spinal clonidine: It has been shown that epidural and spinal administration of clonidine in surgical patients enhances quality and duration of neuraxial anaesthesia, reduces dose of local anaesthetic as well as other neuraxial additives such as opioids. It also produces a short period of postoperative analgesia and lowers the dose of systemic postoperative analgesics.

Neurotoxicity has not been reported following the use of intrathecal clonidine and generally the drug is considered to be safe in this regard. Although, subarachnoid administration of clonidine has not been approved by the FDA or any other regulatory agency in the world, there are experimental studies that have demonstrated its safety and efficacy when used by this route. Continuous administration of spinal clonidine in Wistar rats during 14 days failed to demonstrate neurotoxic damage.[15,18] In postnatal rats spinal clonidine produces age and dose-dependent analgesia without signs of spinal cord toxicity, even at doses bigger than required for analgesia.

Clinical use of spinal clonidine: To enhance spinal anaesthesia and postoperative pain control clonidine can be injected in the subarachnoid space as an adjuvant drug to opioids or local anaesthetic. A systematic review by Filos KS et al[10] using a wide variety of spinal clonidine doses as adjuvant to subarachnoid bupivacaine, mepivacaine, prilocaine or tetracaine found that 15 to $150 \mu \mathrm{g}$ prolonged in a linear, dose-dependent manner. There were fewer episodes of intraoperative pain with clonidine. Side effects of intrathecal clonidine include sedation, hypotension and a reduction of the heart rate if given in higher doses $(>150 \mathrm{mcg}$ up to $450 \mathrm{mcg}$ ). And if given in very low doses ( $<75 \mathrm{mcg}$ ) very small changes in the desired outcome were observed. Mid dose intrathecal clonidine $(150-75 \mathrm{mcg})$ produces desired effects with very little or no unwarranted side effects at all.

Ropivacaine is a long-acting amide local anaesthetic agent, which produces effects similar to other local anaesthetic via reversible inhibition of sodium ion influx in nerve fibres. Ropivacaine is less lipophilic than bupivacaine and is less likely to penetrate large myelinated nerve fibres, resulting in relatively reduced motor blockade. Thus, Ropivacaine has a greater degree of motor sensory differentiation, which could be useful when motor blockade is undesirable. The reduced lipophilicity is also associated with decreased potential for central nervous system and cardiac toxicity. 
Post-operative pain relief after laparoscopic cholecystectomy by intraperitoneal insufflation of local anaesthetic agents was well documented by Louizos et al[19] and Uzunkov A et al[20] and Hasaniya NW et al[21] and Lee IO et al[22], Boddy AP et al[23] and Joris J et al[24] has also done a systemic review and meta-analysis about the effective timing of incisional and intraperitoneal Bupivacaine. I preferred Ropivacaine over Bupivacaine due to its sensory actions greater than the motor one.

\section{CONCLUSION}

Mean value of incidence of hypotension, bradycardia, shivering, sedation, vomiting, shoulder pain or discomfort, respiratory depression and need for intraoperative analgesic requirement indicated that clonidine as adjuvant with hyperbaric Bupivacaine in spinal anaesthesia combined with intraperitoneal inflation of $20 \mathrm{~mL}$ of $0.5 \%$ Ropivacaine just after insertion of cannula through an irrigation cannula and 2 $\mathrm{mL}$ of $0.5 \%$ Ropivacaine injected at each port site incision at the time of skin stitches when given in proper way can be a very good alternative to general anaesthesia for Laparoscopic Cholecystectomy without any unmanageable difficulty to the patient and ease for the surgeon. Age, sex and weight of the patients produced no change in results. All safety parameters were within manageable ranges and 1 st rescue analgesia was delayed by 12-16 hours minimizing the uses of parental analgesia in the initial post-operative period. The cost factor is also very favourable, so it can be practiced particularly in field situations and remote areas.

\section{REFERENCES}

1. Chiary A, Eisenach JC. Spinal anesthesia: mechanisms, agents, method and safety. Reg Anesth Pain Med 1998;23(4):357-6, discussion 384-7.

2. Grandhe RP, Wig J, Yaddanapudi LN. Evaluation of bupivacaine-clonidine combination for unilateral spinal anesthesia in lower limb orthopedic surgery. J Anaesth Clin Pharmacol 2008;24:155-8.

3. McGlade DP, Kalpokas MV, Mooney PH, et al. Comparison of $0.5 \%$ ropivacaine and $0.5 \%$ bupivacaine in lumbar epidural anesthesia for lower limb orthopedic surgery. Anesth Intensive Care 1997;25(3):262-6.

4. Niemi L. Effects of intrathecal clonidine on duration of spinal anaesthesia, hemodynamic and postoperative analgesia in patients undergoing knee arthroplasty. Acta Anesthesiol Scand 1994;38(7):724-8.

5. Sethi BS, Samuel M, Sreevastava D. Efficacy of analgesic effects of low dose intrathecal clonidine as adjuvant to bupivacaine. Indian J Anaesth 2007;51(5):415-9.

6. Matsuki A. Noting new under the sun - a Japanese pioneer in the clinical use of intrathecal morphine. Anesthesiology 1983;58(3):289-90.

7. Yaksh TL, Rudy TA. Analgesia mediated by a direct spinal action of narcotics. Science 1976; 192 (4246):1357-8.

8. Filos KS, Goudas LC, Patroni O, et al. Hemodynamic and analgesic profile after intrathecal clonidine in humans. A dose-response study. Anesthesiology 1994;81(3):591601, discussion 27A-28A.
9. Van Tuijl I, van Klei WA, van der Werff DB, et al. The effect of additional intrathecal clonidine to hyperbaric bupivacaine on postoperative pain and morphine requirement after caesarean section: a randomized controlled trial. Br J Anaesth 2006;97(3):365-70.

10. Bloor B. Clonidine and other alpha2 adrenergic agonists: and important new drug class for the perioperative period. Sem Anesth 1988;7:170-7.

11. Eisenach JC, De Kock M, Klimscha W. Alpha (2)adrenergic agonists for regional anesthesia. A clinical review of clonidine (1984-1995). Anesthesiology 1996;85(3):655-74.

12. Mavropoulos G, Minguet G, Brichant JF. Interest for alpha-2 adrenoreceptors agonists in anaesthesia and intensive care medicine. Rev Med Liege 2014;69(2):97101.

13. Ochs G, Loew M, Tonn J, et al. Distribution, tolerability and tissue compatibility of intrathecal tizanidine in the sheep. Acta Anaesthesiol Scand 1998;42(7):786-93.

14. Flordellis C, Manolis A, Scheinin M, et al. Clinical and pharmacological significance of alpha 2-adrenoceptor polymorphisms in cardiovascular diseases. Int J Cardiol 2004;97(3):367-72.

15. Odagaki Y, Toyoshima R. Pharmacological characterization of alpha 2D-adrenergic receptormediated [35S] GTP gamma S binding in rat cerebral cortical membranes. Pharmacol Res 2008;57(6):435-44.

16. Pettinger WA. Pharmacology of clonidine. J Cardiovasc Pharmacol 1980;2(Suppl 1):S21-8.

17. Houston MC. Clonidine hydrochloride. South Med J 1982;75(6):713-9.

18. Robinson ES, Nutt DJ, Hall L, et al. Autoradiographical and behavioral effects of a chronic infusion of antisense to the alpha2D-adrenoceptor in the rat. Br J Pharmacol 1999;128(3):515-22.

19. Louizos AA, Hadzilia SJ, Leandros E, et al. Post-operative pain relief after laparoscopic cholecystectomy. Surg Endosc 2005;19(11):1503-6.

20. Uzunkoy A, Coskun A, Akinci OF. The value of preemptive analgesia in the treatment of postoperative pain after laparoscopic cholecystectomy. Eur Surg Res 2001;33(1):39-41.

21. Hasaniya NW, Zayed FF, Faiz H, et al. Pre-insertion local anaesthesia at the trocar site improves perioperative pain and decreases costs of laparoscopic cholecystectomy. Surg Endosc 2001;15(9):962-4.

22. Lee IO, Kim SH, Kong MH, et al. Pain after laparoscopic cholecystectomy; the effect and timing of incisional and intraperitoneal bupivacaine. Can J Anaesth 2001;48(6):545-50.

23. Boddy AP, Mehta S, Rhodes M. The effect of intraperitoneal local anaesthesia in laparoscopic cholecystectomy: a systemic review and meta-analysis. Anesth Analg 2006;103(3):682-8.

24. Joris J, Thiry E, Paris P, et al. Pain after laparoscopic cholecystectomy: characteristics and effect of intraperitoneal bupivacaine. Anesth Analg 1995;81 (2):379-84. 